\section{Concepto de blindaje endodóntico: consideraciones restauradoras en Endodoncia}

\author{
Endodontic shielding concept: \\ restorative considerations in \\ Endodontics
}

José Edgar Valdivia 1,a, Manoel Eduardo de Lima Machado 2,b

${ }^{1}$ Universidade de São Paulo, Faculdade de Odontologia. São Paulo, Brasil.

a Especialista y Magister en Endodoncia.

${ }^{\mathrm{b}}$ Especialista y Doctor en Endodoncia.

\section{Correspondencia:}

José Edgar Valdivia

Correo electrónico: jedgar30@usp.br

Universidade de São Paulo, Faculdade de Odontologia. Av. Prof. Lineu Prestes, 2227 - Cidade Universitária, São Paulo, SP, Brasil.

Recibido: 18/07/19

Aceptado: $02 / 08 / 19$

Publicado: $27 / 11 / 19$
El enfoque integrado de los procedimientos endodónticos y restauradores del elemento dental permite la reincorporación del mismo tratado endodónticamente, a su función en el sistema estomatognático. El diente despulpado no se debilita por los cambios nano-mecánicos en su estructura, tales como, rigidez, módulo de elasticidad y humedad. Lo que puede volverlo más friable es la pérdida de estructura dental por caries, preparación y extensión de la cavidad. De este modo, el blindaje radicular y coronario busca recuperar la resistencia estructural del diente tratado endodónticamente.

El concepto de blindaje corono-radicular propone la colocación de espigos intra-radiculares y el sellado coronario con materiales con propiedades similares a los de la estructura dental perdida ${ }^{1}$. Esto es importante porque el reemplazo dentinario proporciona resistencia mecánica al diente tratado endodónticamente. Por lo tanto, la tendencia de los tratamientos endodónticos contemporáneos es realizar preparaciones y desgastes radiculares más conservadores ${ }^{2}$ y la preparación para el retenedor debe seguir esta tendencia.

La introducción de técnicas de preparación utilizando la fresa o broca recomendada por el fabricante y las puntas ultrasónicas permiten desgastes dentinarios planificados y específicos ${ }^{3}$ favoreciendo la retención mecánica de los espigos en el espacio para el retenedor ${ }^{4}$. Por lo tanto, en la técnica de preparación del espacio para el retenedor, bajo el concepto de desgaste dentinario mínimo, se debe considerar principalmente el conocimiento de la anatomía dental interna. De esta manera, la posibilidad de cometer errores, como desgaste excesivo, desviaciones y perforaciones radiculares, será mínima.

Los espigos intra-radiculares tienen la función de retener las restauraciones coronarias y distribuir las tensiones de masticación a lo largo del eje de la raíz ${ }^{5}$. En este caso, los espigos de fibra de vidrio se usan ampliamente para la restauración de dientes tratados endodónticamente y se han vuelto muy populares por los resultados estéticos satisfactorios y algunas propiedades ventajosas en relación a los espigos metálicos ${ }^{6}$. Por otro lado, la principal desventaja de los espigos pre-fabricados es la adaptación del espigo a la anatomía del conducto radicular. En esas situaciones, se busca anatomizar el espigo al canal, para eso tenemos los espigos fibro-resinosos (resina compuesta reforzando al espigo de fibra de vidrio pre-fabricado), espigos en cerómero (brava block o Grandio Blocs) y espigo de fibra de vidrio (FiberCad) obtenidos a partir de sistemas CAD-CAM con el fin de mejorar la adaptación y retención friccional de los espigos a las paredes del conducto radicular ${ }^{7}$.

Se sabe que los espigos intra-radiculares no aumentan la resistencia de la estructura dental remanente en los 
dientes tratados endodónticamente. Por el contrario, pueden disminuir la resistencia de acuerdo con el diseño del espigo; como por ejemplo, los espigos cilíndricos, pueden debilitar la raíz en relación a la cantidad de dentina eliminada durante la preparación. Los espigos cónicos presentan una configuración que es compatible con la preparación cónica del conducto radicular después de la instrumentación y, de esta manera, permiten una adecuada preservación de la estructura radicular del diente, especialmente en la región apical.

El uso de materiales adhesivos y resinosos actuales permiten la simplificación de la técnica de restauración del diente tratado endodónticamente. Así, la introducción de materiales tipo BULK y CORE permiten un incremento mayor del material restaurador con una contracción de polimerización mínima y una mejor adaptación del material a la cavidad ${ }^{8}$. De este modo, la asociación de espigos de fibra de vidrio, fibro-resinosos con materiales resinosos permiten la construcción de una unidad mecánicamente homogénea, ya que todos los elementos involucrados tienen un comportamiento mecánico similar y propiedades similares. Otro punto importante es la reducción del costo del tratamiento en sesión única con estos materiales en comparación con los procedimientos protésicos en múltiples sesiones de tratamiento.

El uso del aislamiento absoluto es esencial durante el tratamiento endodóntico incluyendo todas las etapas operatorias. En ese sentido, los procedimientos restauradores, como la cementación de espigos intra-radiculares y colocación de materiales resinosos realizados en esta condición, favorecen los resultados satisfactorios ${ }^{9}$, ya que la cadena aséptica se mantiene, evitando la contaminación de los conductos radiculares por bacterias del medio bucal. También se sabe que, el vapor de humedad de la saliva puede perjudicar la adhesión de los materiales restauradores del conducto radicular.

Otro problema relacionado con los dientes tratados endodónticamente es la microfiltración coronaria y la contaminación bacteriana que se produce cuando los dientes tratados no son restaurados en un tiempo prudente después del tratamiento endodóntico, lo que puede comprometer el resultado del tratamiento endodóntico y se posiciona como un factor predisponente para el fracaso ${ }^{10}$. Por lo tanto, la restauración inmediata del diente tratado endodónticamente, que consideramos como blindaje dentario inmediato, se muestra como un factor de impacto en el éxito del tratamiento endodóntico.
De modo general, el blindaje endodóntico, radicular y coronario, incluye la planificación endo-restauradora desde un punto de vista diagnóstico, la preparación mecanizada simultánea del conducto y del espacio para el retenedor intra-radicular, la obturación apical, la cementación de espigos intra-radiculares y la restauración directa o indirecta de forma integrada y simultánea. De este modo, la visión de la Endodoncia con respecto a la preparación y restauración tanto radicular como coronaria debe considerarse en la rehabilitación de los dientes tratados endodónticamente.

\section{Referencias bibliográficas}

1. Valdivia JE, Machado MEL. Simultaneous crown-root shielding in endodontics: from root preparation to coronary restoration. Dental Press Endod. 2017;7(1):32-42.

2. Zanesco C, Só MV, Schmidt S, Fontanella VR, Grazziotin-Soares R, Barletta FB. Apical Transportation, Centering Ratio, and Volume Increase after Manual, Rotary, and Reciprocating Instrumentation in Curved Root Canals: Analysis by Micro-computed Tomographic and Digital Subtraction Radiography. J Endod. 2017;43(3):486-490.

3. Valdivia JE, Machado MEL. Conceitos e técnicas atuais no preparo para retentores intra-radiculares de fibra de vidro. Rev Assoc Paul Cir Dent. 2018;72(2):164-70.

4. Valdivia JE, Vasquez-Jeri R, Salas HE, Machado MEL. Influencia de la técnica de preparación ultrasónica en la adaptación de pernos de fibra de vidrio cónicos. Odont UCE. 2016;1(19):20-28.

5. Santos-Filho PC, Veríssimo C, Raposo LH, Noritomi MecEng PY, Marcondes Martins LR. Influence of ferrule, post system, and length on stress distribution of weakened root-filled teeth. J Endod. 2014;40(11):1874-8.

6. Goracci C, Ferrari M. Current perspectives on post systems: a literature review. Aust Dent J. 2011;56(1):77-83.

7. Valdivia JE, Sánchez GM, Jeri RMV, James AA, Nabeshima CK, Machado MEL. Avaliação da resistência de união à parede dentinária de pinos de fibra de vidro anatomizados em canais ovais longos. Braz Oral Res. 2017;31(supl 2):292.

8. Czasch P, Ilie N. In vitro comparison of mechanical properties and degree of cure of bulk fill composites. Clin Oral Investig. 2013;17(1):227-35.

9. Goldfein J, Speirs C, Finkelman M, Amato R. Rubber dam use during post placement influences the success of root canal-treated teeth. J Endod. 2013;39(12):1481-4.

10. Ray HA, Trope M. Periapical status of endodontically treated teeth in relation to the technical quality of the root filling and the coronal restoration. Int Endod J 1995;28(1):12-8. 